\title{
Psychometric and Structural Validity of the Pittsburgh Sleep Quality Index among Filipino Domestic Workers
}

\author{
Peng Xiong ${ }^{1,2}$, Adam P. Spira ${ }^{3}$ and Brian J. Hall ${ }^{2,4, *(1)}$ \\ 1 Division of Medical Psychology and Behavioral Sciences, Department of Public Health and Preventive \\ Medicine, School of Medicine, Jinan University, Guangzhou 510632, China; paulxiongwhu@gmail.com \\ 2 Global and Community Mental Health Research Group, Department of Psychology, \\ The University of Macau, Macau (SAR) 999078, China \\ 3 Department of Mental Health, Johns Hopkins Bloomberg School of Public Health, Department of Psychiatry \\ and Behavioral Sciences, Johns Hopkins School of Medicine, Johns Hopkins Center on Aging and Health, \\ Baltimore, MD 21205, USA; aspira@jhu.edu \\ 4 Department of Health, Behavior and Society, Johns Hopkins Bloomberg School of Public Health, \\ Baltimore, MD 21205, USA \\ * Correspondence: brianhall@um.edu.mo
}

Received: 31 March 2020; Accepted: 23 June 2020; Published: 20 July 2020

\begin{abstract}
Objectives: Evaluate the psychometric properties and structural validity of the Filipino version of the Pittsburgh Sleep Quality Index (PSQI) among Filipino domestic workers (FDWs). Methods: In Study 1, 131 FDWs completed PSQI and other scales, along with 10-day actigraphic assessment with accompanying electronic daily sleep dairy. A subsample of 61 participants completed follow-up assessment after 10 days. In Study 2, 1363 FDWs were recruited and randomized into two halves. Exploratory factor analysis (EFA) and Confirmatory factor analysis (CFA) were used in the two halves, respectively. Results: In Study 1, the Cronbach's alpha of the PSQI was 0.63 at baseline and 0.67 at follow-up. Test-retest reliability for the PSQI global score based on intraclass correlation was 0.63 . Convergent validity was supported by the significant associations between the PSQI global score, PSQI components scores, sleep patterns from the daily sleep diary, and measures of depression, anxiety, and rumination. Small correlations between the PSQI global score and measures of daytime sleepiness, social support, and self-reported height, supported discriminant validity. In Study 2, EFA yielded two PSQI factors with acceptable factor loadings. CFA established that this two-factor model, comprised of perceived sleep quality and sleep efficiency, evidenced better model fit than alternative models tested. The Cronbach's alpha of two factors was 0.70 and 0.81 , respectively. Conclusions: The PSQI demonstrated good internal consistency of two factors, and good convergent, and divergent validity. Results can be referenced in future studies to measure and screen sleep dysfunction among clinical and non-clinical populations in the Philippines.
\end{abstract}

Keywords: PSQI; validity; CFA; EFA; Filipina domestic workers

\section{Background}

The healthcare-related burden of impaired sleep is enormous. Studies increasingly link inadequate sleep and sleep disorders like insomnia to increased risk of depression, and other mood disorders [1-3], as well as increased fatigue [4], reduced psychomotor performance [5], poor memory consolidation [6], and substantial workplace cost due to work underperformance and absenteeism [7].

Migrant workers are likely to experience increased risk of poor sleep and consequent poor health. Migrant workers, especially domestic workers, may be exposed to sleep deprivation due to on-call 
nature of their work, even during nighttime hours, exposure to traumatic stress, worries about family separation, and long working hours in general [8-11]. However, the literature on migrant worker sleep problems is scarce. One cross-sectional study about transnational Latino migrant farmworkers revealed that $11 \%$ reported daytime sleepiness [12]. In a prevalence study of sleep problems among asylum seekers and refugees, more than half of them $(75.5 \%)$ reported moderate to severe sleep disturbance [13]. The absence of data on the prevalence of sleep-related problems among transnational migrants is a significant gap in the sleep literature.

Currently, there are 2.3 million Filipino domestic workers (FDWs) across the world [14]. One previous study with 32 migrant Filipino live-in caregivers (average age $=51$ years old) in the US reported average low sleep quality ( 3.3 out of 5 based on a five-point sleep quality questionnaire) along with excessive daytime sleepiness (40.0\%) [15]. Evidence from other studies also suggests that labor migrants experience insomnia, sleep deprivation, and poor sleep quality, accompanied by high levels of anxiety and depression [16,17]. Based on the updated 2018 by the Labour Affairs Bureau, Macao Special Administration Region (SAR), there are 27,348 non-resident domestic workers in Macao. Among them, 52.06\% $(14,238)$ come from the Philippines (http://www.dsal.gov.mo). The principle reason for migration from the Philippines is to seek better economic circumstances and improved financial support for their families [18]. Several studies conducted in Macao found a high ( $>25 \%)$ prevalence of anxiety and depression [19]. posttraumatic stress disorder [11], and a $5 \%$ prevalence of gambling problems [20], and discrimination was associated with these disorders [21]. All of these disorders can exacerbate sleep problems.

A study of 290 FDWs in Hong Kong measured their mental health symptoms and revealed that they were suffering much from loneliness, worry, lack of social support, and sleeping difficulties [22]. However, no previous study has attempted to validate a sleep measure among the large Filipino migrant labor force. Quantifying the burden of sleep impairment requires valid and reliable scales.

The Pittsburgh Sleep Quality Index (PSQI) is one of the most widely used self-report sleep measures and has 19 items designed to evaluate subjective sleep quality over the past month [23]. The questionnaire contains seven component scores that range from 0 to 3: 'subjective sleep quality,' 'sleep latency,' 'sleep duration,' 'habitual sleep efficiency,' 'sleep disturbances,' 'use of sleeping medication,' and 'daytime dysfunction.' The seven component scores are summed to obtain a global score ranging from 0-21. Based on the original study, scores larger than 5 indicate poor sleep quality, which yielded a specificity of $86.5 \%$ and a sensitivity of $89.6 \%$ in distinguishing good and poor sleepers [23]. Higher scores on each component indicate poorer sleep. This scale has been translated into many different languages and is a well-established scale with acceptable psychometric properties among numerous clinical and non-clinical populations [24-26].

Although the PSQI was originally introduced as an instrument with a unidimensional factor structure [23], studies debated whether two- or three-factor model better represents impaired sleep than a single factor model [27-30]. A summary of previous factor structure studies are summarized in Table 1. Taken together, there is no clear evidence of a best fitting model for the PSQI.

We performed two studies to evaluate the psychometric and structural validity of PSQI. Study 1 aimed to evaluate the psychometric properties of the PSQI among FDWs. In study 2, the primary aim was to examine the factor structure of the PSQI using exploratory and confirmatory factor analytic methods in this population. The secondary aim was to compare the relative fit of the alternative one-, two-, or three-factor structural models of the PSQI found in previous studies.

\section{Methods}

\subsection{Participants}

In Study 1, a total of 131 female Filipino domestic workers (FDWs) were recruited using snowball sampling from March 2016 to September 2016 in Macao (SAR), People's Republic of China. All participants answered the baseline questionnaires, and 61 of them were invited to complete the 
PSQI once again after 10 days. The data of this study was a part of a larger study utilizing actigraphy to determine the burden of sleep dysfunction and related correlates, along with several embedded validation studies $[11,19,21]$ and a pilot study for the larger planned respondent driven sampling (RDS) project [20,31-33].

In Study 2, the data with 1363 FDWs was obtained from a RDS project conducted in Macao (SAR) from November 2016 to November 2017.

The studies were approved by the ethics committee of the University of Macau. The research process and objectives were explained to the participants before the informed consent was acquired.

\subsection{Measures}

In Study 1, the Filipino versions of the PSQI and Epworth Sleep Scale (ESS) were provided by the Mapi Research Trust (https://eprovide.mapi-trust.org). Official translated versions of the PHQ-9 and GAD-7 were obtained from Pfizer [34]. The Ruminative Response Scale (RRS) and Multi-Dimensional Scale of Perceived Social Support (MSPSS) were translated into Filipino following standard forward and backwards translation guidelines, including cognitive interviews, and pilot testing [35]. Actigraphy and daily sleep diaries were used in Study 1. In Study 2, only PSQI questionnaire data and demographic information were used.

- Objective Sleep:

The Actiwatch-2 (Philips Respironics, Bend, OR, USA) is a widely used wrist-worn sleepmonitoring device, validated against PSG, and used to monitor sleep patterns and individual sleep quality [36]. All the participants wore the actigraph on the wrist of their non-dominant hand for 10 continuous days with 30 seconds epoch length. We only used data from eight nights, removing weekend nights, which reflect different sleep patterns. The following outcome variables are generated: total sleep time (TST), sleep onset latency (SL); sleep efficiency (SE); wake after sleep onset (WASO); number of wake bouts (WB); and fragmentation index (FI), which is an indication of the degree of sleep fragmentation (detailed in Table 2).

- Daily Sleep Diary

This consisted of self-reported TST, bedtime and wake time, SL (assessed on a 5-point ordinal item ranging from 'less than 15 minutes' to 'more than 120 minutes'), sleep quality (SQ) (assessed on a 5-point ordinal item ranging from 'very good' to 'very bad'), TIB (the total time spent in bed), and SE (detailed in Table 2). The diary records of bedtime and wake time were also used to clean the sleep logs in Actiwatch-2. Daily sleep diary was received via online survey sent using short message service twice per day (morning and evening).

\section{- Depressive Symptoms}

The Patient Health Questionnaire with nine items (PHQ-9) is a self-report screening measure used to assess depressive symptoms occurring in the past two weeks. Each item is rated from 0 (not at all) to 3 (nearly every day). Higher total scores indicate greater depression symptom severity [37]. The Filipino version of PHQ-9 was used in a previous study among FDWs in Macao with a good internal consistency (Cronbach's alpha $=0.79)[38]$, and validity [19,39]. The Cronbach's alpha in the present study was 0.78 indicating good internal consistency reliability.

- Anxiety

The Generalized Anxiety Disorder scale with seven items (GAD-7) was used to measure anxiety symptoms [40]. Each item is rated from 0 (not at all) to 3 (nearly every day), with an anxiety symptom severity score from 0 to 21 . The Filipino version of GAD-7 was used in the previous study among FDWs in Macao with a good internal consistency (Cronbach's Alpha $=0.80$ ) [38], and validity [19]. The Cronbach's alpha in the present study was 0.82 indicating good internal reliability. 
- $\quad$ Epworth Sleepiness Scale:

The Epworth Sleepiness Scale (ESS) is an 8-item self-report questionnaire to measure daytime sleepiness in adults [41,42]. Items range from ( 0 'never' to 3 'high chance') to reflect subjects' probability of falling asleep in eight different situations (e.g., while sitting or reading, watching television, and driving). The total score of ESS ranges from 0 to 24, with higher scores indicating greater daytime sleepiness [41]. The Cronbach's alpha in the present study was 0.82 , indicating good internal reliability.

- Rumination

The Ruminative Response Scale (RRS) short version describes rumination that is self-focused, symptom-focused, and focused on the possible causes and consequences of dysphoric mood [43]. Each of the 10 items is rated on a Likert scale ranging from 1 (almost never) to 4 (almost always). The total score ranges from 10 to 40 . Higher total scores reflect greater self-reported rumination. In the present study we omitted one item of 'write down what you are thinking about and analyze it' based on community feedback during the translation and cultural adaptation process as migrant workers thought it was not typical for them to do. The Cronbach's alpha of RRS in the present study was 0.93, indicating excellent internal reliability.

- $\quad$ Perceived social support

The Multi-Dimensional Scale of Perceived Social Support (MSPSS) is a 12-item scale to assess perceived social support [44]. This measure consists of three subscales that examine perceived support from family (four items), friends (four items) and a significant other (four items). Respondents answer on a 7-point scale, from 1 (very strongly disagree) to 7 (very strongly agree). The Cronbach's alpha in the present study was 0.89 , indicating good internal reliability.

Participant characteristics included self-reported age, years working as a domestic worker in Macao, marital status, education level, type of visa, Cantonese fluency (speaking and understanding), monthly salary, weekly working hours, numbers of days off per month, and residence (i.e., live in or outside of the employer's house).

\section{Data Analysis}

\subsection{Study 1}

We computed descriptive statistics for participants' demographic information. All variables were checked for normality. Pearson correlation was conducted for the relationships between normally distributed variables. Spearman's rho was used for the relationships between non-normally distributed variables. Item-level missing data for the PSQI was observed for 3 participants. The missing data of PSQI was dealt with using listwise deletion given that less than $5 \%$ missingness was observed in the sample [45].

\subsubsection{Reliability Testing}

Internal consistency reliability was assessed using Cronbach's alpha for the seven PSQI components scores. The values over 0.60 are considered acceptable [46]. Item-to-total correlations (ITC) were calculated to assess the internal homogeneity of the scale. Each component score of PSQI was treated as one separate item. ITC values higher than 0.30 are acceptable [47]. The test-retest reliability was assessed by ICC with baseline PSQI global and component scores and paired 10-day retest scores. A nonparametric bootstrap was used to obtain the $95 \%$ confidence interval (CI) of ICC. ICC values higher than 0.75 are considered strong, values from 0.40 to 0.75 are moderate, and values less than 0.40 are considered poor reliability [48]. 


\subsubsection{Validity Testing}

Convergent validity refers to associations between two measures that are theoretically related. This was tested with correlations between the PSQI global score and PHQ-9, GAD-7, and RRS. Based on previous literature, we hypothesized that: (a) greater depressive symptom severity would correlate with worse sleep dysfunction [49]; (b) greater anxiety symptom severity would correlate with worse sleep dysfunction [50]; (c) greater level of rumination would correlate with worse sleep dysfunction [51]. Convergent validity was also examined by the associations between the follow-up of PSQI global and component scores and averaged daily sleep parameters from the Actiwatch-2 and sleep diary, separately. We hypothesized that the variables of TST, SL, SE from Actiwatch-2 and daily sleep diary would be significantly associated with PSQI components of 'sleep duration', 'sleep latency', and 'habitual sleep efficiency', respectively.

Discriminant validity refers to the expected lower association between constructs due to their lack of theoretical relation. This was assessed by correlating the PSQI global score with the ESS, MSPSS and self-reported height. A previous study evidenced poor correlation between ESS and PSQI global [28], this might due to the different goal of ESS, which measures habitual sleepiness rather than actual sleep symptoms [52]. We hypothesized that there would be the negligible correlations between the PSQI global and ESS [28], MSPSS [53] and self-reported height, respectively.

\subsection{Study 2}

The basic psychometric properties of the PSQI including Cronbach's alpha, componentto-component correlations (Spearman's rho), and component-to-total correlations (Spearman's rho) were assessed. Construct validity of PSQI was separated into two parts, EFA and CFA.

The participants were randomly divided into two halves with the RAND formula in Excel. EFA was conducted on the first random sample. Before conducting factor analysis procedures, the suitability of performing factor analysis was assessed based on Bartlett test of sphericity, $p<0.001$ and the Kaiser-Meyer-Olkin (KMO) of sampling adequacy $=0.64$ [54]. EFA was performed using principal component analysis with maximum likelihood estimation to identify the latent factors that explain the common and unique variance of the 19 items of PSQI. An oblimin rotation procedure was conducted. Factors were extracted based on eigenvalues above 1 [55]. The item loading values equal to or greater than 0.3 were retained.

To verify the factor structure of PSQI, CFA was then conducted on the second random sample to assess the fitness of the structural model based on the identified model obtained in the EFA. The weighted least squares mean and variance adjusted (WLSMV) estimator was used as that the PSQI components scores are ordinal rather than continuous [56]. The adequate goodness of fitness indexes of the model was evaluated and based on standard benchmarks, including the chi-square test of the model (the $\mathrm{p}$ value greater than 0.05 would be preferred), comparative fit index $(\mathrm{CFI})>=0.90$, Tucker-Lewis index (TLI) $>=0.90$, root mean square error of approximation (RMSEA) $<=0.08$, and standardized root mean square residual (SRMR) $<=0.08$ [57,58]. We also calculated the goodness of fit of other models from the previous studies to make comparisons to other samples. For the best model, the standardized estimated of the factor loading paths was summarized in Figure 1. Descriptive statistics and EFA procedures were conducted with STATA 14.0 (Stata Corp, College Station, TX, US). CFA was conducted using Mplus [59]. All the statistical significance level was set as $p$ value $<0.05$ with two tails.

\section{Results}

\subsection{Study 1}

One hundred and thirty-one FDWs with an average age of 39.7 years $(\mathrm{SD}=8.3$; median $=39$; range $=21-59)$ participated in this study. Their average height was $155.7 \mathrm{~cm}(\mathrm{SD}=6$; median $=157.5$; range $=130-183)$. The majority $(58.02 \%)$ of participants reported to have at least some college or higher educational attainment. The average length as a domestic worker in Macao was 5.1 years $(\mathrm{SD}=3.6$; 
median $=4)$. The average monthly salary was $488.4(\mathrm{SD}=107.1$; median $=480)$ USD. The reported average weekly working hours were $69.1(\mathrm{SD}=20.1$; median $=70)$. More than half $(59.5 \%)$ lived outside of their employer's home.

\subsubsection{Reliability}

The Cronbach's alpha of the PSQI global scale was 0.63 at baseline $(n=131)$ and 0.67 at follow-up $(\mathrm{n}=61)$. According to alpha if item deleted analysis, the reliability slightly increased (0.64) either when the component of 'use of sleeping medication' or 'habitual sleep efficiency' was omitted (see Table 3). The coefficients of item-to-total correlation ranged from 0.37 ('use of sleeping medication') to 0.66 ('subjective sleep quality' and 'sleep latency'). The 10-day ICC of the PSQI global score was 0.63. The ICC values of the PSQI component scores ranged from 0.30 ('use of sleeping medicine') to 0.58 ('sleep latency' and 'sleep duration').

\subsubsection{Validity}

The detailed results of discriminant validity of PSQI are shown in Table 4. The detailed results of convergent validity of PSQI are given in Tables 4 and 5. No actigraphy variables were found significantly associated with the follow-up of PSQI global and component scores, except inverse correlations between PSQI 'sleep duration' and Actiwatch-2 TST $\left(r_{s}=-0.65, p<0.01\right)$ and WB $(r=-0.43, p<0.01)$, which show consistency in reporting (higher PSQI scores indicate shorter sleep time).

\subsection{Study 2}

\subsubsection{Participants Characteristics}

Participant characteristics are presented in Table 6.

\subsubsection{EFA Results}

The EFA results are displayed in Table 7. Based on the eigenvalue $>=1$, two factors were obtained, which explained $33.99 \%$ and $22.25 \%$ variance of data, respectively. Each PSQI component had an acceptable loading, which ranged from 0.38 to 0.77 . Five components loaded high on factor 1 , which was named 'perceived sleep quality.' Two components loaded high on factor 2, which was named 'sleep efficiency'. This result was the same as that reported by Magee et al. [30].

\subsubsection{CFA Results}

The two-factor model identified through the result of EFA was tested. We also compared our model with the original one-factor [23] and other two- [28,60] and three-factor models $[27,29,61]$. Table 8 presented the goodness-fit indices of each PSQI model with second random half of the sample. From the results, the two-factor model based on EFA results presented good fit: CFI $=0.96$, TLI $=0.94$, RMSEA $=0.065$, SRMR $=0.039$. However, original one-factor and other two-factor models provided poor fit to the data (see Table 8).

The replicated three-factor model from Gelaye et al. [61] also presented acceptable fit: CFI $=0.94$, $\mathrm{TLI}=0.90, \mathrm{RMSEA}=0.050, \mathrm{SRMR}=0.093$. However, the standardized path coefficient (1.59) between factor 1 'perceived sleep quality' and factor 3 'daytime disturbances' of the model was greater than 1 . This result suggested that the factor 1 and factor 3 might have overlapping concepts and should be combined to be one, which was consistent with the EFA identified two-factor model. Figure 1 showed the standardized path coefficients of the two-factor model of PSQI.

\subsubsection{Basic Psychometric Properties of PSQI}

PSQI global scores of 1363 participants ranged from 0 to 17 , with the mean score of 6.28 (SD = 3.24). The Cronbach's alpha of PSQI factor 'perceived sleep quality' and 'sleep efficiency' was 0.70 and 0.81 , respectively. Table 9 provided more detailed information. 
Table 1. The two- or three- structure models of Pittsburgh Sleep Quality Index from the previous studies.

\begin{tabular}{|c|c|c|c|c|c|}
\hline Study (Year) [Reference] & Population & Sample Size & Type of Structure Model & Results & Added Paths (Modifications) \\
\hline Magee et al. (2008) [30] & $\begin{array}{c}\text { Australian adults aged } 18 \text { to } 59 \\
\text { years old }\end{array}$ & 364 & two-factor & $\begin{array}{c}\text { Perceived sleep quality }(\mathrm{C} 1, \mathrm{C} 2, \mathrm{C} 5, \mathrm{C} 6, \mathrm{C} 7) \\
\text { Sleep efficiency }(\mathrm{C} 3, \mathrm{C} 4)\end{array}$ & \\
\hline Kotronoulas et al. (2011) [28] & $\begin{array}{l}\text { Patients with cancer } \\
\text { receiving chemotherapy }\end{array}$ & 209 & two-factor & $\begin{array}{l}\text { Quality of nocturnal sleep: C1, C2, C3, C4, C5; } \\
\text { Daily disturbances and management of sleep } \\
\text { problems: C6, C7. }\end{array}$ & \\
\hline Guo et al. (2016) [51] & Chinese undergraduate students & 631 & two-factor & Same as Magee et al. (2008). & \\
\hline Qiu et al. (2016) [62] & US pregnant women & 1488 & two-factor & $\begin{array}{l}\text { Factor1: C1, C2, C3, C4; } \\
\text { Factor2: C5, C7. }\end{array}$ & $\mathrm{C} 2$ and $\mathrm{C} 4, \mathrm{C} 3$ and $\mathrm{C} 4$ \\
\hline Becker et al. (2017) [63] & $\begin{array}{l}\text { Portuguese community-dwelling } \\
\text { older adults }\end{array}$ & 204 & two-factor & $\begin{array}{l}\text { Perceived sleep quality: C1, C2; } \\
\text { Sleep efficiency: C3, C4; } \\
\text { Daytime function: C5, C7. }\end{array}$ & \\
\hline Fontes et al. (2017) [60] & Portuguese breast cancer patients & 474 & two-factor & $\begin{array}{l}\text { Factor1: C1, C2, C3, C4; } \\
\text { Factor2: C5, C6, C7. }\end{array}$ & \\
\hline Passos et al. (2017) [64] & Brazilian adolescents & 309 & two-factor & $\begin{array}{l}\text { Same as Magee et al. (2008) omitting the sleep } \\
\text { medication component }\end{array}$ & \\
\hline Otte et al. (2013) [65] & $\begin{array}{l}\text { Non-depressed breast } \\
\text { cancer survivors }\end{array}$ & 1174 & two-factor & Same as Magee et al. (2008). & $\begin{array}{l}\mathrm{C} 1 \text { and } \mathrm{C} 3, \mathrm{C} 2 \text { and } \mathrm{C} 4, \mathrm{C} 2 \text { and } \\
\mathrm{C} 6, \mathrm{C} 2 \text { and } \mathrm{C} 7, \mathrm{C} 3 \text { and } \mathrm{C} 7 \text {. }\end{array}$ \\
\hline Gelaye et al. (2014) [61] & $\begin{array}{l}\text { Undergraduate students in Chile, } \\
\text { Ethiopia, and Thailand }\end{array}$ & 5900 & two-factor & Same as Magee et al. (2008). & \\
\hline Cole et al. (2006) [27] & Community-dwelling adults & 417 & three-factor & $\begin{array}{l}\text { Perceived sleep quality: } \mathrm{C} 1, \mathrm{C} 2, \mathrm{C} 6 \text {, } \\
\text { Sleep efficiency }(\mathrm{C} 3, \mathrm{C} 4) \\
\text { Daily disturbances }(\mathrm{C} 5, \mathrm{C} 7)\end{array}$ & \\
\hline Mariman et al. (2012) [66] & $\begin{array}{l}\text { Chronic fatigue } \\
\text { syndrome patients }\end{array}$ & 413 & three-factor & Same as Cole et al. (2006). & \\
\hline Gelaye et al. (2014) [61] & Undergraduate students in Peru & 2581 & three-factor & $\begin{array}{l}\text { Sleep quality: C1, C5, C7; } \\
\text { Sleep efficiency: C3, C4; } \\
\text { Other: } \mathrm{C} 2, \mathrm{C} 6 \text {. }\end{array}$ & \\
\hline Koh et al. (2015) [29] & $\begin{array}{l}\text { Multi-ethnicities population } \\
\text { in Singapore }\end{array}$ & 489 & three-factor & $\begin{array}{l}\text { Perceived sleep quality: C1, C2; } \\
\text { Sleep efficiency: C3, C4; } \\
\text { Daytime function: C5, C6, C7. }\end{array}$ & \\
\hline Otte et al. (2015) [67] & Women with hot flashes & 890 & three-factor & Same as Cole et al. (2006). & \\
\hline Zhong et al. (2015) [68] & Peruvian Pregnant Women & 642 & three-factor & $\begin{array}{l}\text { Perceived sleep quality: C1, C2, C5, C7; } \\
\text { Sleep efficiency: C3, C4; } \\
\text { Sleep medication: C1, C2, C6. }\end{array}$ & \\
\hline
\end{tabular}

Note: $\mathrm{C} 1$ = 'subjective sleep quality', C2 = 'sleep latency', C3 = 'sleep duration', C4 = 'habitual sleep efficiency', C5 = 'sleep disturbances', C6 = 'use of sleeping medication', C7 = 'daytime dysfunction'. 
Table 2. Sleep patterns from actigraphy and daily sleep diary.

\begin{tabular}{|c|c|c|c|}
\hline Sleep Patterns & Description & Actigraphy & Daily Sleep Diary \\
\hline Total sleep time (TST) & $\begin{array}{c}\text { The total amount of sleep obtained from falling asleep to final awakening (reported in } \\
\text { hours and minutes). }\end{array}$ & $\sqrt{ }$ & \\
\hline The time in bed (TIB) & $\begin{array}{c}\text { It was calculated by the interval period between the time to wake up and the reported } \\
\text { bedtime the night before. }\end{array}$ & & $\sqrt{ }$ \\
\hline Sleep onset latency (SL) & The time between bedtime and sleep onset (reported in minutes). & $\sqrt{ }$ & $\sqrt{ }$ \\
\hline Sleep efficiency (SE) & The result of TST divided by the total time in bed $\times 100 \%$ & $\sqrt{ }$ & $\sqrt{ }$ \\
\hline Wake after sleep onset (WASO) & The number of minutes scored as awake during the sleep period after initial sleep onset. & $\sqrt{ }$ & \\
\hline Number of wake bouts (WB) & The number of contiguous epochs categorized as wake. & $\sqrt{ }$ & \\
\hline Fragmentation index (FI) & The sum of the 'mobile time $(\%)^{\prime}$ and the 'immobile bouts $<=1 \mathrm{~min}(\%)^{\prime}$. & $\sqrt{ }$ & \\
\hline Sleep quality (SQ) & Item from PSQI, 'During the past month, how would you rate your sleep quality overall?' & & $\sqrt{ }$ \\
\hline
\end{tabular}

Table 3. Item characteristics, item-total correlation, alpha if item deleted, 10-day test-retest reliability of PSQI.

\begin{tabular}{|c|c|c|c|c|c|c|}
\hline Items & Mean & Standard Deviation & Item-To-Total Correlation $^{b}$ & Alpha if Item Deleted & ICC & $95 \%$ CI of ICC \\
\hline Component 1: Subjective sleep quality & 1.13 & 0.63 & 0.66 ** & 0.55 & $0.44 * *$ & $(-0.07,0.91)$ \\
\hline Component 2: Sleep latency & 1.46 & 0.86 & $0.66^{* *}$ & 0.56 & $0.58^{* *}$ & $(0.05,1.13)$ \\
\hline Component 3: Sleep duration & 1.37 & 0.90 & $0.63^{* *, a}$ & 0.58 & $0.58^{* *}$ & $(0.09,1.08)$ \\
\hline Component 4: Habitual sleep efficiency & 0.45 & 0.74 & $0.43^{* * a}$ & 0.64 & $0.35 * *$ & $(-0.27,0.99)$ \\
\hline Component 5: Sleep disturbances & 1.51 & 0.61 & $0.52 * *$ & 0.59 & 0.43 ** & $(-0.25,1.10)$ \\
\hline Component 6: Use of sleeping medicine & 0.27 & 0.62 & $0.37^{* *, \mathrm{a}}$ & 0.64 & $0.30 * *$ & $(-0.18,0.73)$ \\
\hline Component 7: Daytime dysfunction & 0.88 & 0.70 & $0.59 * *$ & 0.57 & $0.42 * *$ & $(-0.21,1.03)$ \\
\hline PSQI-Global (0-21) & 7.09 & 2.86 & & & $0.63^{* *}$ & $(0.01,1.24)$ \\
\hline
\end{tabular}

Note: Overall Cronbach's alpha of PSQI is 0.63 at baseline and 0.67 at 10 -day retest. ${ }^{*}=p<0.05, * *=p<0.01 .{ }^{\text {a }}=$ Spearman's correlation, ${ }^{\mathrm{b}}=$ Pearson correlation. CI $=$ confidential interval.
ICC $=$ intraclass correlation coefficient. Each component score ranges from 0 to 3 . Item-to-total correlation means the correlations between each component and the PSQI-Global score. 
Table 4. Discriminant and convergent validity of the PSQI at baseline $(n=131)$

\begin{tabular}{|c|c|c|c|c|c|c|c|c|c|}
\hline \multirow{2}{*}{ PSQI Items } & \multirow{2}{*}{ PHQ-9 a } & \multirow{2}{*}{ GAD-7 ${ }^{a}$} & \multirow{2}{*}{ ESS $^{\mathrm{a}}$} & \multirow{2}{*}{ RRS $^{a}$} & \multicolumn{3}{|c|}{ MSPSS } & \multirow[b]{2}{*}{ Other $^{a}$} & \multirow{2}{*}{ Height } \\
\hline & & & & & Total $^{\mathbf{a}}$ & Family $^{a}$ & Friends ${ }^{a}$ & & \\
\hline Component 1 & $0.27 * *$ & $0.26^{* *}$ & -0.06 & $0.21 *$ & -0.23 ** & $-0.25^{* *}$ & -0.17 & -0.16 & 0.09 \\
\hline Component 2 & 0.13 & 0.06 & 0.07 & 0.20 * & -0.21 * & $-0.27^{* *}$ & -0.13 & -0.12 & 0.09 \\
\hline Component 3 & 0.13 & 0.10 & 0.05 & 0.10 & -0.17 & -0.18 * & -0.17 & -0.07 & 0.003 \\
\hline Component 4 & -0.06 & -0.03 & 0.07 & 0.12 & -0.04 & -0.13 & 0.03 & 0.07 & $0.22 *$ \\
\hline Component 5 & $0.38^{* *}$ & $0.31^{* *}$ & 0.11 & $0.38^{* *}$ & .06 & 0.10 & 0.03 & 0.05 & 0.03 \\
\hline Component 6 & $0.23 * *$ & $0.23 * *$ & $0.24^{* *}$ & 0.19 * & -0.05 & -0.03 & -0.01 & -0.09 & 0.10 \\
\hline Component 7 & $0.47^{* *}$ & $0.29 * *$ & 0.19 * & $0.38^{* *}$ & -0.11 & -0.11 & -0.19 & -0.10 & 0.12 \\
\hline PSQI-Global & $0.36^{* *}$ & $0.28 * *$ & 0.17 & $0.39^{* *}$ & -0.18 * & $-0.21 *$ & -0.15 & -0.07 & 0.18 * \\
\hline
\end{tabular}

Note: ${ }^{*}=\overline{p<0.05,{ }^{*}=p<0.01 .}{ }^{a}=$ Spearman's correlation. Component $1=$ 'subjective sleep quality', Component $2=$ 'sleep latency', Component $3=$ 'sleep duration', Component $4=$ 'habitual sleep efficiency', Component $5=$ 'sleep disturbances', Component $6=$ 'use of sleeping medication', Component $7=$ 'daytime dysfunction', and PSQI-Global = the global score of PSQI. PHQ-9 = Patient Health Questionnaire-9. GAD-7 = Generalized Anxiety Disorder-7. ESS = Epworth Sleep Scale. RRS = Ruminative Response Scale. MSPSS = Multi-Dimensional Scale of Perceived Social Support.

Table 5. Convergent validity of PSQI at 10-day retest $(n=61)$.

\begin{tabular}{|c|c|c|c|c|c|c|c|c|c|c|c|}
\hline \multirow{2}{*}{$\begin{array}{l}\text { Follow-Up } \\
\text { PSQI Items }\end{array}$} & \multicolumn{4}{|c|}{ Sleep Diary $(\mathrm{n}=58)$} & \multirow[b]{2}{*}{$\mathrm{SE}^{\mathrm{a}}$} & \multicolumn{6}{|c|}{ Actigraphic Variables $(n=61)$} \\
\hline & TIB $^{b}$ & $\mathrm{SL}^{\mathrm{a}}$ & TST $^{b}$ & $S Q^{a}$ & & TST $^{a}$ & $\mathrm{SL}^{\mathrm{a}}$ & $\mathrm{SE}^{\mathrm{a}}$ & WASO $^{a}$ & $\mathbf{W B}^{\mathbf{b}}$ & FI $^{\mathbf{b}}$ \\
\hline Component 1 & $-0.27 *$ & $0.31 *$ & $-0.27 *$ & $0.61^{* *}$ & 0.19 & -0.11 & 0.14 & -0.07 & 0.04 & -0.10 & 0.15 \\
\hline Component 2 & -0.19 & $0.62 * *$ & -0.23 & $0.44^{* *}$ & $0.34^{* *}$ & -0.09 & 0.16 & -0.16 & 0.17 & -0.07 & 0.15 \\
\hline Component 3 & $-0.80^{* *}$ & 0.25 & $-0.79 * *$ & $0.36^{* *}$ & 0.16 & $-0.65^{* *}$ & -0.09 & 0.13 & -0.24 & $-0.43^{* *}$ & -0.06 \\
\hline Component 4 & $-0.29 *, \mathrm{a}$ & 0.15 & $-0.31 * *, \mathrm{a}$ & $0.30 *$ & 0.19 & 0.02 & -0.01 & 0.02 & -0.05 & $-0.09^{\mathrm{a}}$ & $0.09^{\mathrm{a}}$ \\
\hline Component 5 & -0.10 & $0.28 *$ & -0.06 & $0.46^{* *}$ & 0.12 & -0.04 & -0.09 & 0.07 & 0.04 & -0.09 & 0.03 \\
\hline Component 6 & / & / & / & I & / & 0.15 & 0.12 & -0.18 & 0.22 & $0.09^{a}$ & $0.18^{\mathrm{a}}$ \\
\hline Component 7 & -0.13 & 0.30 * & $-0.09 * *$ & $0.44^{* *}$ & -0.10 & -0.11 & 0.14 & -0.07 & 0.01 & -0.02 & 0.02 \\
\hline PSQI-Global & $-0.48^{* *}$ & $0.48 * *$ & $-0.48^{* *}$ & $0.65^{* *}$ & 0.25 & -0.23 & 0.03 & 0.02 & -0.03 & -0.21 & 0.14 \\
\hline
\end{tabular}

Note: ${ }^{*}=p<0.05,{ }^{* *}=p<0.01 .{ }^{\mathrm{a}}=$ Spearman's correlation, ${ }^{\mathrm{b}}=$ Pearson correlation. No correlations are calculated between component 6 and sleep diary since no participants reported medical use in the study. Component $1=$ 'subjective sleep quality', Component $2=$ 'sleep latency', Component 3 = 'sleep duration', Component $4=$ 'habitual sleep efficiency', Component 5 $=$ 'sleep disturbances', Component $6=$ 'use of sleeping medication', Component $7=$ 'daytime dysfunction', and PSQI-Global = the global score of PSQI. For the variables of sleep dairy, TIB = 'the total time spent in bed', $\mathrm{SL}=$ 'sleep onset latency', TST = 'total sleep time', SQ = 'self-report sleep quality', and SE = 'sleep efficiency'. For the actigraphy variables, $\mathrm{TST}$ = 'total sleep time in bed', SL = 'sleep onset latency', SE = 'sleep efficiency', WASO = 'wake after sleep onset', WB = 'wake bouts', and FI = 'fragmentation index'. 
Table 6. Participant Characteristics for the total sample and random samples used in factor analysis $(\mathrm{n}=1363)$.

\begin{tabular}{|c|c|c|c|}
\hline Selected Variables & $\begin{array}{l}\text { Total Sample } \\
(n=1363)\end{array}$ & $\begin{array}{l}\text { Sample for EFA } \\
\qquad(n=681)\end{array}$ & $\begin{array}{l}\text { Sample for CFA } \\
\qquad(\mathrm{n}=682)\end{array}$ \\
\hline Age (years, mean $\pm \mathrm{SD}$ ) & $40.99 \pm 8.92$ & $40.79 \pm 8.87$ & $41.19 \pm 8.97$ \\
\hline \multicolumn{4}{|l|}{ Age group } \\
\hline $18-30$ & $188(13.79)$ & $92(13.51)$ & $96(14.08)$ \\
\hline $31-40$ & $491(36.02)$ & $256(37.59)$ & $235(34.46)$ \\
\hline $41-50$ & $482(35.36)$ & $233(34.21)$ & $249(36.51)$ \\
\hline$\geq 51$ & $202(14.82)$ & $100(14.68)$ & $102(14.96)$ \\
\hline Time working as a domestic worker in Macao (years) & $6.07 \pm 8.60$ & $6.16 \pm 8.86$ & $5.97 \pm 8.34$ \\
\hline \multicolumn{4}{|l|}{ Marital status } \\
\hline Single, never married & $347(25.46)$ & $175(25.70)$ & $172(25.22)$ \\
\hline Married & $603(44.24)$ & $302(44.35)$ & $301(44.13)$ \\
\hline Partnered but not married & $97(7.12)$ & $46(6.75)$ & $51(7.48)$ \\
\hline Separated & $214(15.70)$ & $100(14.68)$ & $114(16.72)$ \\
\hline Legally separated & $9(0.66)$ & $6(.88)$ & $3(0.44)$ \\
\hline Widowed & $93(6.82)$ & $52(7.64)$ & $41(6.01)$ \\
\hline \multicolumn{4}{|l|}{ Education level } \\
\hline Elementary & $24(1.76)$ & $11(1.62)$ & $13(1.91)$ \\
\hline High school & $489(35.88)$ & $244(35.83)$ & $245(35.92)$ \\
\hline Technical/vocational & 147 (10.79) & $72(10.57)$ & $75(11.00)$ \\
\hline 2-year associate degree & 209 (15.33) & $107(15.71)$ & $102(14.96)$ \\
\hline Some college & $225(16.51)$ & $116(17.03)$ & 109 (15.98) \\
\hline Bachelor's degree & $265(19.44)$ & $130(19.09)$ & 135 (19.79) \\
\hline Master's degree or higher & $4(0.29)$ & $1(0.15)$ & $3(0.44)$ \\
\hline \multicolumn{4}{|l|}{ Type of Visa } \\
\hline Working Visa & $1358(99.63)$ & $678(99.56)$ & $680(99.71)$ \\
\hline Temporary permanent resident & $3(0.22)$ & $2(0.29)$ & $1(0.15)$ \\
\hline Permanent resident & $2(0.15)$ & $1(0.15)$ & $1(0.15)$ \\
\hline Language speaking level (Cantonese) & $1.64 \pm 1.76$ & $1.63 \pm 1.76$ & $1.64 \pm 1.75$ \\
\hline Language understanding level (Cantonese) & $1.72 \pm 1.88$ & $1.72 \pm 1.91$ & $1.71 \pm 1.85$ \\
\hline \multicolumn{4}{|l|}{ Live-in / live-out } \\
\hline Live-in & $672(49.30)$ & $333(48.90)$ & $339(49.71)$ \\
\hline Live-out & $691(50.70)$ & $348(51.50)$ & $343(50.29)$ \\
\hline Monthly salary (USD) & $436.93 \pm 101.31$ & $436.72 \pm 108.46$ & $437.14 \pm 93.70$ \\
\hline Working hours per week & $65.60 \pm 21.99$ & $66.55 \pm 22.51$ & $64.66 \pm 21.44$ \\
\hline Numbers of days off per month & $3.71 \pm 1.77$ & $3.71 \pm 1.13$ & $3.71 \pm 1.23$ \\
\hline
\end{tabular}

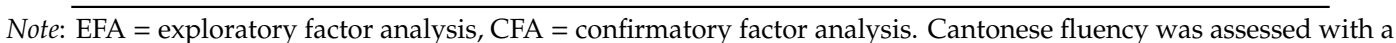
ruler scale, which ranged from the lowest level (0) to the highest level (10). "Live-in/live-out" was asked by "Do you live in your employer's home?".

Table 7. The factor loadings in exploratory factor analysis of Pittsburgh Sleep Quality Index $(n=681)$.

\begin{tabular}{ccc}
\hline PSQI Items & Factor 1 & Factor 2 \\
\hline Component 1: Subjective sleep quality & $\mathbf{0 . 6 2}$ & 0.16 \\
Component 2: Sleep latency & $\mathbf{0 . 4 8}$ & 0.11 \\
Component 3: Sleep duration & 0.13 & $\mathbf{0 . 7 7}$ \\
Component 4: Habitual sleep efficiency & 0.00 & $\mathbf{0 . 7 7}$ \\
Component 5: Sleep disturbances & $\mathbf{0 . 5 8}$ & 0.03 \\
Component 6: Use of sleeping medicine & $\mathbf{0 . 3 8}$ & 0.08 \\
Component 7: Daytime dysfunction & $\mathbf{0 . 6 0}$ & 0.05 \\
\% Variance explained & $33.99 \%$ & $22.25 \%$ \\
\hline
\end{tabular}

Table 8. Models evaluated for the Pittsburgh Sleep Quality Index and goodness-of-fit indices using confirmatory factor analysis $(n=682)$.

\begin{tabular}{cccccccc}
\hline & Models & $\chi^{2}$ & df & CFI & TLI & RMSEA & SRMR \\
\hline \multirow{3}{*}{ The second random sample } & One-factor $^{2}$ & $466.20^{* *}$ & 14 & 0.55 & 0.33 & 0.22 & 0.12 \\
& Two-factor $^{\text {a }}$ & $\mathbf{5 0 . 7 5 ^ { * * }}$ & $\mathbf{1 3}$ & $\mathbf{0 . 9 6}$ & $\mathbf{0 . 9 4}$ & $\mathbf{0 . 0 6 5}$ & $\mathbf{0 . 0 3 9}$ \\
& Two-factor $^{\mathrm{b}}$ & $457.24^{* *}$ & 13 & 0.56 & 0.29 & 0.22 & 0.11 \\
\hline & Two-factor $^{c}$ & $464.13^{* *}$ & 13 & 0.55 & 0.28 & 0.23 & 0.11 \\
& Three-factor $^{\mathrm{a}}$ & $83.29^{* *}$ & 12 & 0.93 & 0.88 & 0.050 & 0.093 \\
& Three-factor $^{\mathrm{b}}$ & $72.42^{* *}$ & 12 & 0.94 & 0.90 & 0.048 & 0.086 \\
& Three-factor $^{\mathrm{c}}$ & $83.78^{* *}$ & 12 & 0.93 & 0.88 & 0.084 & 0.05 \\
\hline
\end{tabular}

Note: CFI = comparative fit index, TLI = Tucker-Lewis index, RMSEA = root mean square error of approximation, SRMR $=$ standardized root mean square residual. Two-factor ${ }^{\mathrm{a}}$ model was identified through EFA results. Two-factor ${ }^{b}$ model is from Kotronoulas et al. (2011) [28]. Two-factor ${ }^{c}$ model is from Fontes et al. (2017) [60]. Three-factor ${ }^{a}$ model is from Cole et al. (2006) [27]. Three-factor ${ }^{\mathrm{b}}$ model is from Gelaye et al. (2014) [61]. Three-factor ${ }^{\mathrm{c}}$ model is from Koh et al. (2015) [29]. 
Table 9. The descriptive and correlation statistic of Pittsburgh Sleep Quality Index $(n=1363)$.

\begin{tabular}{|c|c|c|c|c|c|c|c|c|c|}
\hline PSQI Items & 1 & 2 & 3 & 4 & 5 & 6 & 7 & 8 & 9 \\
\hline 1.Component 1: Subjective sleep quality & 1 & & & & & & & & \\
\hline 2. Component 2: Sleep latency & $0.41 * *$ & 1 & & & & & & & \\
\hline 3. Component 3: Sleep duration & $0.23 * *$ & $0.14^{* *}$ & 1 & & & & & & \\
\hline 4. Component 4: Habitual sleep efficiency & $0.08^{* *}$ & 0.04 & $0.60^{* *}$ & 1 & & & & & \\
\hline 5. Component 5: Sleep disturbances & $0.39 * *$ & $0.38^{* *}$ & $0.13^{* *}$ & 0.01 & 1 & & & & \\
\hline 6. Component 6: Use of sleeping medicine & $0.16^{* *}$ & 0.04 & $0.09 * *$ & $0.09^{* *}$ & $0.24 * *$ & 1 & & & \\
\hline 7. Component 7: Daytime dysfunction & $0.39 * *$ & $0.28^{* *}$ & $0.16^{* *}$ & $0.06 *$ & $0.38^{* *}$ & $0.26^{* *}$ & 1 & & \\
\hline 8. PSQI factor 1 & 0.73 ** & $0.75^{* *}$ & NA & NA & $0.71^{* *}$ & $0.24 * *$ & $0.68^{* *}$ & 1 & \\
\hline 9. PSQI factor 2 & NA & NA & $0.91^{* *}$ & $0.85^{* *}$ & NA & NA & NA & NA & 1 \\
\hline Mean & 0.79 & 1.29 & 1.29 & 0.83 & 1.28 & 0.27 & 0.54 & 3.89 & 2.12 \\
\hline Standard deviation & 0.63 & 0.83 & 1.00 & 1.13 & 0.67 & 0.65 & 0.67 & 2.04 & 1.96 \\
\hline Median & 1 & 1 & 1 & 0 & 1 & 0 & 0 & 4 & 1 \\
\hline IQR & $0-1$ & $1-2$ & $1-2$ & $0-1$ & $1-2$ & $0-0$ & $0-1$ & $2-5$ & $1-3$ \\
\hline
\end{tabular}

Note: ${ }^{*}=p<0.05,{ }^{* *}=p<0.01$. IQR $=$ Interquartile range. $\mathrm{NA}=$ no correlation is presented since items were included in the PSQI factor. Each component score ranges from 0 to 3. All the correlations were Spearman's rho coefficients.

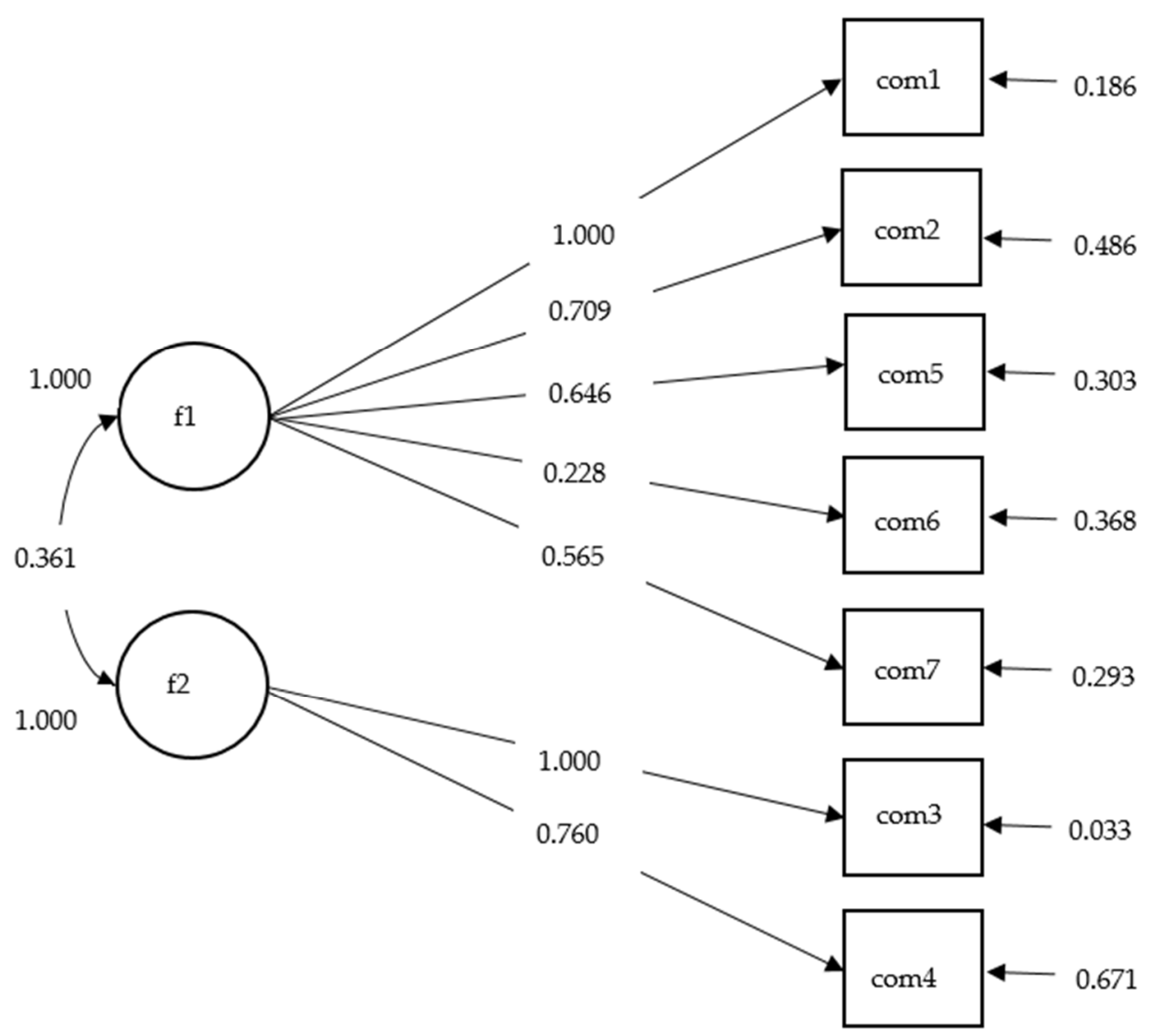

Figure 1. The standardized path coefficients of two-factor model of the Pittsburgh Sleep Quality Index among FDWs in Macao, China $(\mathrm{n}=682)$. Note: Factor1 is perceived sleep quality, factor 2 is sleep efficiency. Com1 = 'subjective sleep quality', com2 = 'sleep latency', com3 = 'sleep duration', com $4=$ 'habitual sleep efficiency', com5 = 'sleep disturbances', com $6=$ 'use of sleeping medicine', $\operatorname{com} 7=$ 'daytime dysfunction.

\section{Discussion}

To our knowledge, this is the first study to assess the psychometric properties and the factorial validity of Filipino version of the PSQI. The results demonstrated a low internal consistency of the PSQI global score, but acceptable values for the two PSQI factors. Our literature review revealed a wide arrange of Cronbach alpha of PSQI from 0.57 to $0.89[24,25,68]$. Measures with low alpha may still be useful [69]. The 10-day test-retest ICC values for the PSQI global and component scores 
demonstrated moderate reliability except for the components of 'habitual sleep efficiency' and 'use of sleeping medicine', which suggested that sleep is stably assessed using the PSQI global score and some of the component scores within this population.

Overall, 'subjective sleep quality' and 'sleep latency' components were most highly correlated with the global score, and components of 'use of sleeping medicine' and 'habitual sleep efficiency' were least correlated with the global score of PSQI. This pattern of associations suggests that the global score of PSQI reflects 'subjective sleep quality' and 'sleep latency' more than other components and that 'use of sleeping medicine' and 'habitual sleep efficiency' are less reliable, consistent with previous studies $[62,68]$. This is likely due to the infrequent use of sleep medication in this sample (less than $20 \%$ reported its use).

The PSQI demonstrated good convergent validity in our sample. Greater sleep dysfunction was significantly associated with higher levels of depression and anxiety, similar to previous research [70]. The PSQI global score and many components were found significantly and moderately associated with RRS. The reason could be explained that these two scales might have conceptional overlap. The RRS assesses respondents' reflection and brooding on the possible causes and consequences of dysphoric mood [43]. Its association with sleep quality was approved and illustrated among undergraduate students with findings that rumination factors like worry might contribute to cognitive activity, which could affect sleep quality [71].The adequate convergent validity of the PSQI was also supported by the moderate associations between PSQI follow-up and sleep diary variables, which were shown not only on the PSQI global score, but also on other components. We would expect daily assessments of sleep dysfunction to demonstrate higher test-retest reliability than aggregated retrospective reports of sleep problems [72], so the high correlations between daily diary reports and PSQI scores obtained at 10-day follow-up indicate strong reliability for self-reported sleep problems in the sample. In particular, self-reported SQ, SL, and TST were especially highly correlated. This was consistent with previous study findings that sleep patterns of sleep diaries had the high correlations with PSQI items [73].

For actigraphy variables, we only found that longer TST and more WB were significantly associated with longer PSQI 'sleep duration'. The results were consistent with the previous criterion validity study of PSQI among non-clinical population, which found no significant correlation results between PSQI global and actigraphy variables of TST, SE, WASO, and SL, but significant associations between PSQI sleep duration and TST, as measured by the actigraphy [74]. Similarly, the original PSQI validation study showed a lack of association between the PSQI and PSG with the strongest correlation being $r=0.30$ between the PSQI and PSG SL [23]. The possible reasons might be that actigraphy or PSG measures actual sleep in real time while the PSQI is retrospective recall measurement, which may hinder accuracy and have reporting biases. Moreover, the low correlations ranging from 0.28 to 0.32 between PSQI components and PSG sleep parameters also supported the difference between objective sleep measures and self-report measures [73].

Discriminant validity was demonstrated by small effect size correlations $(<0.30)$ between the PSQI global score and MSPSS and self-report height. Even some significant associations between PSQI and MSPSS-total and MSPSS-family were found, the associations were still weak. The result was consistent with the previous validation study [53].

The present study also examined the factor structure of the Filipino version of PSQI. The EFA identified two factors within the PSQI, which were labeled 'perceived sleep quality' for the first factor including the PSQI components of 'subjective sleep quality,' 'sleep latency,' 'sleep disturbances,' and 'daytime dysfunction', and the term 'sleep efficiency' for the second factor, which including 'sleep duration' and 'habitual sleep efficiency'. Subsequent CFA evidenced that this two-factor model along with the three-factor model [61] were favored statistically over the original one-factor model [23] and other published two-factor models [28,60]. Although the three-factor model from Gelaye et al. [61] had similar model fit with the our two-factor model, the model fit suggested combining the 'perceived sleep quality' and 'daytime disturbances' factors. The results and process in the present study were similar with the previous studies [30,61]. 
The Cronbach's alpha of PSQI factor 'perceived sleep quality' was 0.70, indicating acceptable internal consistency. The Cronbach's alpha of PSQI factor 'sleep efficiency' was 0.81 , indicating the good internal consistency. All the components showed high component-total correlations with the PSQI factors, which further supported good internal consistency of the PSQI among FDWs.

Investigators previously argued that a two- or three-factor structure of the PSQI might be a better representation of sleep disturbance than a unidimensional model $[27,28,75]$. Our study supported a two- factor structure of PSQI, which was consistent with the two-factor model proposed by previous researchers $[30,61,64]$. Some researchers observed that the removal of 'use of sleeping medication' did not have a major impact on the fitness of the CFA models [30]. However, another structure validation study among 309 Brazilian adolescents showed the best two-structure model of PSQI excluding the component of 'use of sleeping medication' [64]. In our study, the identified two-factor model fit indecencies improved when this component was removed. Of note, the PSQI global score and cut-off score in defining the poor sleep would be changed when removing 'use of sleep medication.' Further studies should explore whether the scale demonstrates incremental validity in assessing sleep dysfunction when 'use of sleep medication' component is included in non-clinical samples.

\section{Conclusions}

Study 1 provided evidence that the Filipino version of PSQI is an adequately reliable and valid assessment instrument useful for quantifying sleep parameters in FDWs. Among the PSQI component scores, the most robust evidence was obtained for 'subjective sleep quality,' 'sleep latency,' and 'sleep duration.' The use of sleep medication is not likely a critical indicator of sleep dysfunction in this population. The findings in Study 2 validated the two-factor structure of the PSQI to assess self-reported subjective sleep disturbance among FDWs. The Filipino version of PSQI scale demonstrated good construct validity. The present study could be referenced for future studies to measure and screen sleep dysfunction among clinical and non-clinical population in the Philippines.

The current study has some notable strengths. It is the first known study to evaluate the psychometric properties and structural validity of PSQI among Filipino transnational migrants or any Filipino sample. Second, the study design included daily diary self-reported sleep assessments. Third, we used actigraphic assessment as an objective indicator of sleep dysfunction. Despite these strengths, the study has several limitations. First, the sample size only included female domestic workers, limiting generalizability to other transnational migrants and men. This two-factor structure of PSQI may not generalize to all Filipinos or Filipino migrant workers, especially men [27-30]. Second, participants were recruited using snowball sampling methods in study 1 , which is likely to introduce some sampling bias. Third, the factorial validity of the measure could not be assessed given the size of the sample. Further studies that asses a more diverse sample of overseas Filipino workers and evaluate the factorial validity of the Filipino version of the PSQI are needed. Fourth, previous studies used one or several self-reported items instead of the full PSQI scale to measure sleep in epidemiological studies [76,77]. Further studies could explore the utility of a brief version of the PSQI among FDWs due to their very busy schedule.

Author Contributions: P.X. and B.J.H. conceived and designed the study. B.J.H. supervised the study. P.X. conducted the data analysis and wrote the manuscript. A.P.S. reviewed and edited the manuscript. B.J.H. reviewed and corrected the manuscript. All authors have read and agreed to the published version of the manuscript.

Funding: This work was supported by the Research and Development Affairs Office, University of Macau, People's Republic of China, under grant NO. MYRG2015-00111-FSS \& NO. MYRG2019-00120-FSS (PI: Hall).

Acknowledgments: We thank the Caritas-Macau, a local non-governmental organization in Macao, to provide us the study site and collaboration. We thank all the research members in the Global and Community Mental Health Research group (GCMH), Department of Psychology, the University of Macau, who contributed in data collection, collaboration, and support during the project implementation. We also thank all the Filipina domestic workers in Macao, for participating and collaborating with us in this research.

Conflicts of Interest: The authors declare no conflict of interest. 
Declarations: Ethical approval and consent to participate: All procedures performed in studies involving human participants were in accordance with the ethical standards of the institutional and with the 1964 Helsinki declaration and its later amendments or comparable ethical standards. The study was approved by the ethics committee of the University of Macau. Informed consent was obtained from all individual participants included in the study.

\section{Abbreviations}

CFA: confirmatory factor analysis; CFI: comparative fit index; CI: confidence interval; EFA: exploratory factor analysis; ESS: Epworth Sleep Scale; FDWs: Filipino domestic workers; FI: fragmentation index; GAD-7: Generalized Anxiety Disorder scale with 7 items; ICC: intraclass correlation coefficient; ITC: item-to-total correlations; KMO: Kaiser-Meyer-Olkin; MSPSS: Multi-Dimensional Scale of Perceived Social Support; PHQ-9: Patient Health Questionnaire with 9 items; PSQI: Pittsburgh Sleep Quality Index; PSG: polysomnography; RMSEA: root mean square error of approximation; RRS: Ruminative Response Scale; SD: standard deviation; SE: sleep efficiency; SL: sleep onset latency; SRMR: standardized root mean square residual; SQ: sleep quality; TLI: Tucker-Lewis index; TST: total sleep time; TTSIB: total time spent in bed last night; WASO: wake after sleep onset; WB: wake bouts; WLSMV: weighted least squares mean and variance adjusted.

\section{References}

1. Skouteris, H.; Wertheim, E.H.; Germano, C.; Paxton, S.J.; Milgrom, J. Assessing sleep during pregnancy: A study across two time points examining the Pittsburgh Sleep Quality Index and associations with depressive symptoms. Womens Health Issues 2009, 19, 45-51. [CrossRef]

2. Shekleton, J.A.; Rogers, N.L.; Rajaratnam, S.M. Searching for the daytime impairments of primary insomnia. Sleep Med. Rev. 2010, 14, 47-60. [CrossRef]

3. Skouteris, H.; Germano, C.; Wertheim, E.H.; Paxton, S.J.; Milgrom, J. Sleep quality and depression during pregnancy: A prospective study. J. Sleep Res. 2008, 17, 217-220. [CrossRef]

4. Broström, A.; Wahlin, Å.; Alehagen, U.; Ulander, M.; Johansson, P. Sex-specific associations between self-reported sleep duration, depression, anxiety, fatigue and daytime sleepiness in an older communitydwelling population. Scand. J. Caring Sci. 2018, 32, 290-298. [CrossRef]

5. Edinger, J.D.; Means, M.K.; Carney, C.E.; Krystal, A.D. Psychomotor performance defcits and their relation to prior nights' sleep among individuals with primary insomnia. Sleep 2008, 31, 599-607. [CrossRef]

6. Walker, M.P.; Stickgold, R. Sleep-dependent learning and memory consolidation. Neuron 2004, 44, 121-133. [CrossRef]

7. Kessler, R.C.; Berglund, P.A.; Coulouvrat, C.; Hajak, G.; Roth, T.; Shahly, V.; Shillington, A.C.; Stephenson, J.J.; Walsh, J.K. Insomnia and the performance of US workers: Results from the America insomnia survey. Sleep 2011, 34, 1161-1171. [CrossRef] [PubMed]

8. Burnham, L.; Theodore, N. Home Economics: The Invisible and Unregulated World of Domestic Work. Available online: https://idwfed.org/en/resources/home-economics-the-invisible-and-unregulated-world-ofdomestic-work/@@display-file/attachment_1 (accessed on 1 January 2020).

9. Hall, B.J.; Garabiles, M.R.; Latkin, C.A. Work life, relationship, and policy determinants of health and well-being among filipino domestic workers in China: A qualitative study. BMC Public Health 2019, 19, 229. [CrossRef]

10. Vargas, M.C.; Garabiles, M.R.; Hall, B.J. Narrative identities of overseas filipino domestic worker community in Macao (SAR) China. J. Community Psychol. 2020, 48, 977-993. [CrossRef] [PubMed]

11. Hall, B.J.; Yip, P.S.Y.; Garabiles, M.R.; Lao, C.K.; Chan, E.W.W.; Marx, B.P. Psychometric validation of the PTSD checklist-5 among female Filipino migrant workers. Eur. J. Psychotraumatol. 2019, 10, 1571378. [CrossRef] [PubMed]

12. Sandberg, J.C.; Grzywacz, J.G.; Talton, J.W.; Quandt, S.A.; Chen, H.; Chatterjee, A.B.; Arcury, T.A. A cross-sectional exploration of excessive daytime sleepiness, depression, and musculoskeletal pain among migrant farmworkers. J. Agromed. 2012, 17, 70-80. [CrossRef]

13. Lies, J.; Drummond, S. Prevalence Study of Sleep Disturbance, Mental Health, and Psychosocial Concerns among Asylum Seekers and Refugees; Journal of Sleep Research, 2017; Wiley: Hoboken, NJ, USA, 2017; pp. 45-46.

14. The Commission on Filipinos Overseas 2015 CFO Statistics on Philippine International Migration. Available online: http://www.cfo.gov.ph/images/pdf/2017/2015compendiumstats-insidepages (accessed on 29 June 2017).

15. Riley, K.; Nazareno, J.; Malish, S. 24-hour care: Work and sleep conditions of migrant Filipino live-in caregivers in Los Angeles. Am. J. Ind. Med. 2016, 59, 1120-1129. [CrossRef] 
16. Hovey, J.D.; Magaña, C. Acculturative stress, anxiety, and depression among Mexican immigrant farmworkers in the Midwest United States. J. Immigr. Health 2000, 2, 119-131. [CrossRef]

17. Tang, J.; Liu, J.; Wu, D.; Deng, X.; Yuan, F. Correlation analysis between sleep quality and anxiety and depression among migrant workers in Shenzhen. Chin. J. Soc. Med. 2010, 27, 362-364.

18. Garabiles, M.R.; Ofreneo, M.A.P.; Hall, B.J. Towards a model of resilience for transnational families of Filipina domestic workers. PLoS ONE 2017, 12, e0183703. [CrossRef]

19. Garabiles, M.R.; Lao, C.K.; Yip, P.; Chan, E.W.W.; Mordeno, I.; Hall, B.J. Psychometric validation of PHQ-9 and GAD-7 in filipino migrant domestic workers in Macao (SAR), China. J. Pers. Assess 2019, 1-12. [CrossRef]

20. Yi, G.; Huang, L.; Lam, A.I.F.; Latkin, C.; Hall, B.J. Spatial and sociodemographic correlates of gambling participation and disorder among female Filipino migrant workers in Macao, People's Republic of China. Addict. Behav. 2019, 97, 49-55. [CrossRef] [PubMed]

21. Hall, B.J.; Pangan, C.A.C.; Chan, E.W.W.; Huang, R.L. The effect of discrimination on depression and anxiety symptoms and the buffering role of social capital among female domestic workers in Macao, China. Psychiat. Res. 2019, 271, 200-207. [CrossRef]

22. Holroyd, E.A.; Molassiotis, A.; Taylor-Pilliae, R.E. Filipino domestic workers in Hong Kong: Health related behaviors, health locus of control and social support. Women Health 2001, 33, 181-205. [CrossRef]

23. Buysse, D.J.; Reynolds, C.F.; Monk, T.H.; Berman, S.R.; Kupfer, D.J. The Pittsburgh Sleep Quality Index: A new instrument for psychiatric practice and research. Psychiatry Res. 1989, 28, 193-213. [CrossRef]

24. Ait-Aoudia, M.; Levy, P.P.; Bui, E.; Insana, S.; de Fouchier, C.; Germain, A.; Jehel, L. Validation of the French version of the Pittsburgh Sleep Quality Index addendum for posttraumatic stress disorder. Eur. J. Psychotraumatol. 2013, 4, 19298. [CrossRef]

25. Manzar, M.D.; Moiz, J.A.; Zannat, W.; Spence, D.W.; Pandi-Perumal, S.R.; Hussain, M.E. Validity of the Pittsburgh Sleep Quality Index in Indian University students. Oman Med. J. 2015, 30, 193-202. [CrossRef]

26. Nakajima, S.; Okajima, I.; Sasai, T.; Kobayashi, M.; Furudate, N.; Drake, C.L.; Roth, T.; Inoue, Y. Validation of the Japanese version of the ford insomnia response to stress test and the association of sleep reactivity with trait anxiety and insomnia. Sleep Med. 2014, 15, 196-202. [CrossRef]

27. Cole, J.C.; Motivala, S.J.; Buysse, D.J.; Oxman, M.N.; Levin, M.J.; Irwin, M.R. Validation of a 3-factor scoring model for the Pittsburgh Sleep Quality Index in older adults. Sleep 2006, 29, 112-116. [CrossRef]

28. Kotronoulas, G.C.; Papadopoulou, C.N.; Papapetrou, A.; Patiraki, E. Psychometric evaluation and feasibility of the Greek Pittsburgh Sleep Quality Index (GR-PSQI) in patients with cancer receiving chemotherapy. Support. Care Cancer 2011, 19, 1831-1840. [CrossRef]

29. Koh, H.W.; Lim, R.B.; Chia, K.S.; Lim, W.Y. The Pittsburgh Sleep Quality Index in a multi-ethnic Asian population contains a three-factor structure. Sleep Breath. Schlaf Atm. 2015, 19, 1147-1154. [CrossRef]

30. Magee, C.A.; Caputi, P.; Iverson, D.C.; Huang, X.F. An investigation of the dimensionality of the Pittsburgh Sleep Quality Index in Australian adults. Sleep Biol. Rhythm. 2008, 6, 222-227. [CrossRef]

31. Garabiles, M.R.; Lao, C.K.; Xiong, Y.; Hall, B.J. Exploring comorbidity between anxiety and depression among migrant Filipino domestic workers: A network approach. J. Affect. Disord. 2019, 250, 85-93. [CrossRef]

32. Garabiles, M.R.; Lao, K.L.; Wang, S.Y.; Hall, B.J. The network structure of posttraumatic stress disorder among Filipina migrant domestic workers: Comorbidity with depression. Eur. J. Psychotraumatol. 2020, 10, 1571378 .

33. Hall, B.J.; Yang, X.; Huang, L.; Yi, G.; Chan, E.W.W.; Tucker, J.D.; Latkin, C.A. Barriers and facilitators of rapid HIV and syphilis testing uptake among Filipino transnational migrants in China. AIDS Behav. 2020, 24, 418-427. [CrossRef]

34. Pfizer Screener Overview. Available online: http://www.phqscreeners.com (accessed on 1 February 2016).

35. World Health Organization. Process of Translation and Adaptation of Instruments. Available online: http://www.who.int/substance_abuse/research_tools/translation/en (accessed on 1 February 2016).

36. Shin, M.; Swan, P.; Chow, C.M. The validity of actiwatch2 and senseWear armband compared against polysomnography at different ambient temperature conditions. Sleep Sci. 2015, 8, 9-15. [CrossRef] [PubMed]

37. Kroenke, K.; Spitzer, R.L.; Williams, J.B. The PHQ-9: Validity of a brief depression severity measure. J. Gen. Intern. Med. 2001, 16, 606-613. [CrossRef] [PubMed]

38. Mendoza, N.B.; Mordeno, I.G.; Latkin, C.A.; Hall, B.J. Evidence of the paradoxical effect of social network support: A study among Filipino domestic workers in China. Psychiatry Res. 2017, 255, 263-271. [CrossRef] 
39. Mordeno, I.G.; Carpio, J.G.E.; Mendoza, N.B.; Hall, B.J. The latent structure of major depressive symptoms and its relationship with somatic disorder symptoms among Filipino female domestic workers in China. Psychiatry Res. 2018, 270, 587-594. [CrossRef]

40. Spitzer, R.L.; Kroenke, K.; Williams, J.B.; Löwe, B. A brief measure for assessing generalized anxiety disorder: The GAD-7. Arch. Intern. Med. 2006, 166, 1092-1097. [CrossRef]

41. Johns, M.W. A new method for measuring daytime sleepiness: The epworth sleepiness scale. Sleep 1991, 14, 540-545. [CrossRef]

42. Johns, M.W. A new perspective on sleepiness. Sleep Biol. Rhythm. 2010, 8, 170-179. [CrossRef]

43. Treynor, W.; Gonzalez, R.; Nolen-Hoeksema, S. Rumination reconsidered: A psychometric analysis. Cogn. Ther. Res. 2003, 27, 247-259. [CrossRef]

44. Zimet, G.D.; Dahlem, N.W.; Zimet, S.G.; Farley, G.K. The multidimensional scale of perceived social support. J. Personal. Assess. 1988, 52, 30-41. [CrossRef]

45. Scheffer, J. Dealing with missing data. In Research Letters in the Information and Mathematical Sciences; Massey University: Auckland, New Zealand, 2002; Volume 3, pp. 153-160.

46. Griethuijsen, R.A.L.F.; Michiel, W.; Helen, H.; Perry, J.; Nigel, C.; Mansour, N.; Ayse, S.; BouJaoude, S. Global patterns in students' views of science and interest in science. Res. Sci. Educ. 2015, 45, 581-603. [CrossRef]

47. DeVellis, R.F. Scale Development: Theory and Applications; Sage Publications: New York, NY, USA, 2016; Volume 26.

48. Weir, J.P. Quantifying test-retest reliability using the intraclass correlation coefficient and the SEM. J. Strength Cond. Res. 2005, 19, 231-240.

49. Kaneita, Y.; Ohida, T.; Uchiyama, M.; Takemura, S.; Kawahara, K.; Yokoyama, E.; Miyake, T.; Harano, S.; Suzuki, K.; Fujita, T. The relationship between depression and sleep disturbances: A Japanese nationwide general population survey. J. Clin. Psychiatry 2006, 67, 196-203. [CrossRef] [PubMed]

50. Rosa, R.R.; Bonnet, M.H.; Kramer, M. The relationship of sleep and anxiety in anxious subjects. Biol. Psychol. 1983, 16, 119-126. [CrossRef]

51. Guo, S.; Sun, W.; Liu, C.; Wu, S. Structural validity of the Pittsburgh Sleep Quality Index in Chinese undergraduate students. Front. Psychol. 2016, 7, 1126. [CrossRef]

52. Tsai, P.-S.; Wang, S.-Y.; Wang, M.-Y.; Su, C.-T.; Yang, T.-T.; Huang, C.-J.; Fang, S.-C. Psychometric evaluation of the Chinese version of the Pittsburgh Sleep Quality Index (CPSQI) in primary insomnia and control subjects. Qual. Life Res. 2005, 14, 1943-1952. [CrossRef]

53. Bush, A.L.; Armento, M.E.; Weiss, B.J.; Rhoades, H.M.; Novy, D.M.; Wilson, N.L.; Kunik, M.E.; Stanley, M.A. The Pittsburgh Sleep Quality Index in older primary care patients with generalized anxiety disorder: Psychometrics and outcomes following cognitive behavioral therapy. Psychiatry Res. 2012, 199, 24-30. [CrossRef] [PubMed]

54. Beavers, A.S.; Lounsbury, J.W.; Richards, J.K.; Huck, S.W.; Skolits, G.J.; Esquivel, S.L. Practical considerations for using exploratory factor analysis in educational research. Pract. Assess. Res. Eval. 2013, 18, 6.

55. Kaiser, H.F. The application of electronic computers to factor analysis. Educ. Psychol. Meas. 1960, 20, 141-151. [CrossRef]

56. Suh, Y. The performance of maximum likelihood and weighted least square mean and variance adjusted estimators in testing differential item functioning with nonnormal trait distributions. Struct. Equ. Model. A Multidiscip. J. 2015, 22, 568-580. [CrossRef]

57. Hu, L.T.; Bentler, P.M. Fit indices in covariance structure modeling: Sensitivity to underparameterized model misspecification. Psychol. Methods 1998, 3, 424-453. [CrossRef]

58. Wood, P. Confirmatory Factor Analysis for Applied Research; Taylor \& Francis: Abingdon, UK, 2008.

59. Muthén, L.K.; Muthén, B.O. Mplus: Statistical Analysis with Latent Variables: User's Guide; Muthén \& Muthén: Los Angeles, CA, USA, 2005.

60. Fontes, F.; Goncalves, M.; Maia, S.; Pereira, S.; Severo, M.; Lunet, N. Reliability and validity of the Pittsburgh Sleep Quality Index in breast cancer patients. Support. Care Cancer 2017, 25, 3059-3066. [CrossRef] [PubMed]

61. Gelaye, B.; Lohsoonthorn, V.; Lertmeharit, S.; Pensuksan, W.C.; Sanchez, S.E.; Lemma, S.; Berhane, Y.; Zhu, X.; Velez, J.C.; Barbosa, C.; et al. Construct validity and factor structure of the pittsburgh Sleep Quality Index and epworth sleepiness scale in a multi-national study of African, South East Asian and South American college students. PLoS ONE 2014, 9, e116383. [CrossRef] [PubMed] 
62. Qiu, C.; Gelaye, B.; Zhong, Q.Y.; Enquobahrie, D.A.; Frederick, I.O.; Williams, M.A. Construct validity and factor structure of the Pittsburgh Sleep Quality Index among pregnant women in a Pacific-Northwest cohort. Sleep Breath. 2016, 20, 293-301. [CrossRef]

63. Becker, N.B.; de Neves Jesus, S. Adaptation of a 3-factor model for the Pittsburgh Sleep Quality Index in Portuguese older adults. Psychiatry Res. 2017, 251, 298-303. [CrossRef] [PubMed]

64. Passos, M.H.; Silva, H.A.; Pitangui, A.C.; Oliveira, V.M.; Lima, A.S.; Araujo, R.C. Reliability and validity of the Brazilian version of the Pittsburgh Sleep Quality Index in adolescents. J. Pediatr. 2017, 93, 200-206. [CrossRef]

65. Otte, J.L.; Rand, K.L.; Carpenter, J.S.; Russell, K.M.; Champion, V.L. Factor analysis of the Pittsburgh Sleep Quality Index in breast cancer survivors. J. Pain Symptom Manag. 2013, 45, 620-627. [CrossRef] [PubMed]

66. Mariman, A.; Vogelaers, D.; Hanoulle, I.; Delesie, L.; Tobback, E.; Pevernagie, D. Validation of the three-factor model of the PSQI in a large sample of chronic fatigue syndrome (CFS) patients. J. Psychosom. Res. 2012, 72, 111-113. [CrossRef]

67. Otte, J.L.; Rand, K.L.; Landis, C.A.; Paudel, M.L.; Newton, K.M.; Woods, N.; Carpenter, J.S. Confirmatory factor analysis of the Pittsburgh Sleep Quality Index in women with hot flashes. Menopause (New York, N.Y.) 2015, 22, 1190-1196. [CrossRef] [PubMed]

68. Zhong, Q.Y.; Gelaye, B.; Sanchez, S.E.; Williams, M.A. Psychometric properties of the Pittsburgh Sleep Quality Index (PSQI) in a cohort of peruvian pregnant women. J. Clin. Sleep Med. 2015, 11, 869-877. [CrossRef]

69. Schmitt, N. Uses and abuses of coefficient alpha. Psychol. Assess. 1996, 8, 350-353. [CrossRef]

70. Takacs, J.; Bodizs, R.; Ujma, P.P.; Horvath, K.; Rajna, P.; Harmat, L. Reliability and validity of the Hungarian version of the Pittsburgh Sleep Quality Index (PSQI-HUN): Comparing psychiatric patients with control subjects. Sleep Breath. 2016, 20, 1045-1051. [CrossRef] [PubMed]

71. Guastella, A.J.; Moulds, M.L. The impact of rumination on sleep quality following a stressful life event. Pers. Individ. Differ. 2007, 42, 1151-1162. [CrossRef]

72. Dietch, J.R.; Taylor, D.J.; Sethi, K.; Kelly, K.; Bramoweth, A.D.; Roane, B.M. Psychometric evaluation of the PSQI in U.S. College Students. J. Clin. Sleep Med. 2016, 12, 1121-1129. [CrossRef]

73. Backhaus, J.; Junghanns, K.; Broocks, A.; Riemann, D.; Hohagen, F. Test-retest reliability and validity of the Pittsburgh Sleep Quality Index in primary insomnia. J. Psychosom. Res. 2002, 53, 737-740. [CrossRef]

74. Grandner, M.A.; Kripke, D.F.; Yoon, I.Y.; Youngstedt, S.D. Criterion validity of the Pittsburgh Sleep Quality Index: Investigation in a non-clinical sample. Sleep Boil. Rhythm. 2006, 4, 129-139. [CrossRef] [PubMed]

75. Aloba, O.O.; Adewuya, A.O.; Ola, B.A.; Mapayi, B.M. Validity of the Pittsburgh Sleep Quality Index (PSQI) among Nigerian university students. Sleep Med. 2007, 8, 266-270. [CrossRef] [PubMed]

76. Zheng, W.; Luo, X.N.; Li, H.Y.; Ke, X.Y.; Dai, Q.; Zhang, C.J.; Ng, C.H.; Ungvari, G.S.; Xiang, Y.T.; Ning, Y.P. Association of sleep duration with sleep disturbances, quality of life, and sociodemographic factors in general hospital outpatients. Perspect. Psychiatr. Care 2018, 54, 422-427. [CrossRef]

77. Wang, S.; Wu, Y.; Ungvari, G.S.; Ng, C.H.; Forester, B.P.; Gatchel, J.R.; Chiu, H.F.K.; Kou, C.; Fu, Y.; Qi, Y.; et al. Sleep duration and its association with demographics, lifestyle factors, poor mental health and chronic diseases in older Chinese adults. Psychiatry Res. 2017, 257, 212-218. [CrossRef]

(C) 2020 by the authors. Licensee MDPI, Basel, Switzerland. This article is an open access article distributed under the terms and conditions of the Creative Commons Attribution (CC BY) license (http://creativecommons.org/licenses/by/4.0/). 